
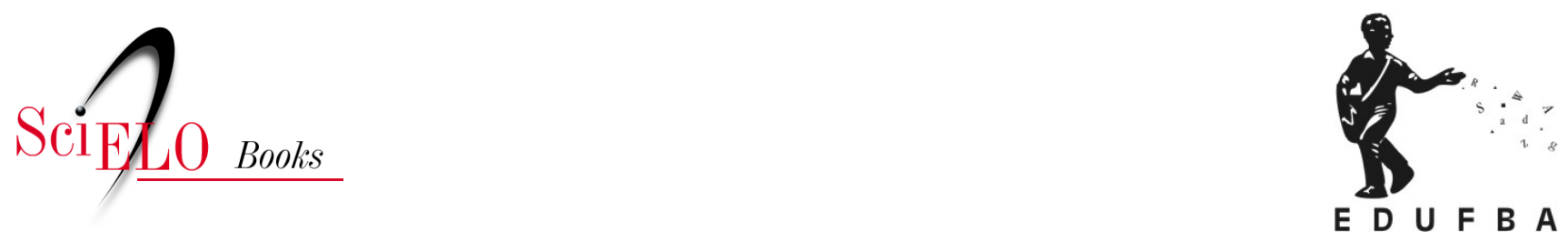

\title{
À guisa de conclusão
}

\author{
Juliana Ortegosa Aggio
}

AGGIO, J.O. À guisa de conclusão. In: Prazer e desejo em Aristóteles [online]. Salvador: EDUFBA, 2017, pp. 275-284. ISBN 978-85-232-2010-5. https://doi.org/10.7476/9788523220105.0009.

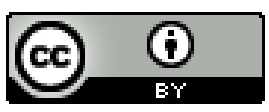

All the contents of this work, except where otherwise noted, is licensed under a Creative Commons Attribution 4.0 International license.

Todo o conteúdo deste trabalho, exceto quando houver ressalva, é publicado sob a licença Creative Commons Atribição 4.0. 


\section{À guisa de conclusão}

À guisa de conclusão, podemos retomar, brevemente, os principais problemas e suas respectivas interpretações. Antes, porém, seria importante ressaltar que a questão principal deste livro, em torno da qual orbitam as demais, diz respeito, de modo geral, à educação do desejo e, mais especificamente, à constituição do bom fim.

Vimos que, para que o fim seja realmente um bem, ele deve ser fruto de uma apreensão racional própria do caráter virtuoso. Isso significa que o fim, objeto de nosso desejo, deve ser também objeto da reta razão (orthos logos), e que o bem concebido verdadeiramente pela razão deve ser também desejado enquanto fim da ação, isto é, deve ser também um bem aparente ou um bem tomado como tal pelo agente moral. Em outros termos, se o objeto natural do desejo é o prazer, com o processo educativo, ele passa a ser o bem verdadeiro independentemente de parecer prazeroso. Isso porque todo objeto se constitui enquanto objeto de desejo na medida em que se mostra sob a forma de um bem, e tomar algo como um bem ou um mal implica, comumente, considerar o prazer e a dor que acompanham ou que poderão acompanhar tal objeto.

Diante desta constatação, a pergunta que surge imediatamente é a seguinte: como podemos desejar a ação por ela ser boa e não por ela ser prazerosa, se desejá-la geralmente significa considerá-la prazerosa? Como podemos desejar o que julgamos ser bom em preferência do que o que percebemos ser prazeroso, uma vez que o bem e não o prazer deve ser o critério para a ação virtuosa? Enfim, como podemos desejar um fim concebido racionalmente? 
Para responder a esta pergunta, Aristóteles, primeiramente, reconhece que o prazer não pode ser o critério determinante da ação, já que ele não existe senão enquanto uma sensação que acompanha uma atividade (energeia). Logo, se o prazer existe apenas como uma espécie de epifenômeno à realização da atividade, então é a atividade que deve ser o objeto do desejo e é sobre ela que deve incidir o julgamento moral. Sendo assim, não é possível julgar se é bom ou não certo prazer, senão a partir do julgamento sobre a atividade acompanhada deste prazer. Ou seja, não há definição possível do valor moral do prazer senão a partir do valor atribuído à atividade. E se Aristóteles faz do julgamento que incide sobre a atividade (e não sobre o prazer) o critério avaliativo do prazer é porque tudo o que ele quer evitar é que tomemos o prazer e a dor como fundamentos do valor moral da ação. Por isso mesmo, a definição do prazer como aquilo que pertence a uma atividade que ele aperfeiçoa, nos permite inferir que o julgamento moral referente à atividade é o critério avaliativo do prazer, e não o contrário, o julgamento do que é prazeroso como critério avaliativo da atividade. Consequentemente, se o prazer não é critério para estabelecer que uma ação seja virtuosa, então o desejo deve aprender a se orientar não pelo que é indiscriminadamente prazeroso, mas antes pelo que determina a reta razão. Sobretudo os chamados desejos mais avessos à razão, o impulso (desejo de enfrentamento da dor) e o apetite (desejo pelo prazeroso), devem se orientar pelo que é belo e conveniente e não pelo que é simplesmente prazeroso ou doloroso, como constatamos na análise das virtudes particulares. Ou seja, o desejo deve aprender a desejar as atividades conforme o bom julgamento moral. Isso significa que devemos nos habituar a ter prazer e dor com o que se deve, como e quando se deve.

Assim, na primeira parte da tese "O prazer segundo Aristóteles", vimos que o desejo jamais poderia ser persuadido pela razão a ter bons objetos, se o prazer fosse considerado o mal ou o bem em absoluto. Se, por um lado, o prazer fosse o bem em absoluto, não haveria necessidade de se educar o desejo a ter prazer apenas com o que se deve, já que ele naturalmente deseja tudo o que é prazeroso e o que é prazeroso seria idêntico ao que é de fato bom. Todavia, o bem não pode ser reduzido ao que consideramos prazeroso. Ademais, o prazer não poderia ser o bem supremo, pois ele é causa necessária, mas não suficiente da felicidade. Por outro lado, se o prazer fosse o mal em absoluto, então jamais poderíamos ter prazer, portanto, apetite pelo que é bom; nem o prazer poderia ser considerado uma das causas da felicidade. Ora, como poderíamos desejar ser virtuosos e felizes, se o nosso desejo estivesse, em grande medida, 
fadado a desejar coisas ruins? Se tudo o que desse prazer também fosse condenável, então tudo o que pudéssemos ter apetite também o seria. Neste caso, o apetite jamais teria como objeto um bem, o que implica dizer que a aquisição da temperança deveria ser considerada impossível. Se nenhum prazer pudesse, por princípio, ser bom, então seria impossível educar o desejo a ter prazer com o que é bom. Seria também inútil educar o desejo se sua natureza não fosse educável, ou seja, se ele não pudesse ter como objeto o que é correto, bom, saudável. O projeto da educação do desejo, por conseguinte, da aquisição da virtude, frente ao anti-hedonismo ou ao hedonismo extremo, estaria fadado ao fracasso e já não poderíamos conceber a ética aristotélica como uma ética das virtudes.

Não parece ser aleatório e, mais do que isso, parece mesmo ser um ganho conceitual diante de seus precedentes, o fato de Aristóteles ter defendido uma tese hedonista moderada, em que o prazer, embora não seja $o$ bem, possa ser um bem, uma vez que esteja acompanhando a realização de uma boa atividade. Enfim, como podemos constatar, é preciso que o prazer possa ser considerado um bem, pois tanto a felicidade, como a virtude são bens e são coisas naturalmente prazerosas. Por isso, o fundamento da educação moral se encontra no fato de que a nossa natureza é educável e de que nós podemos aprender a ter bons prazeres. Em suma, com a análise dos dois Tratados do prazer, concluímos que todo esforço de Aristóteles consiste em defender a possibilidade de o prazer ser um bem, e assim se posicionar por um hedonismo moderado diante do radicalismo anti-hedonista, por um lado, e hedonista, por outro.

Com efeito, vimos que, no primeiro Tratado, Aristóteles se aproxima do hedonismo de Eudoxo com vistas a refutar o anti-hedonismo de Platão e de Espeusipo. Com essa estratégia refutativa, a única tese propositiva que ele formula é a de que o prazer pode ser um bem. Já no segundo Tratado, Aristóteles se dedica a sustentar um hedonismo moderado, distanciando-se do radicalismo hedonista de Eudoxo, ao mostrar que ele é, em parte, falso e, em parte, verdadeiro. A pergunta do primeiro Tratado é a de que se o prazer pode ser um bem ou deveria ser considerado o mal em absoluto. Visto que o prazer é definido, no primeiro Tratado, como um bem por ser uma atividade desimpedida, a pergunta do segundo Tratado é a de que se o prazer poderia ser o bem em absoluto, isto é, a felicidade, pois esta também é uma atividade desimpedida. A reelaboração da definição de prazer, no segundo Tratado, nega a assimilação do prazer à felicidade, pois ele deixa de ser simplesmente uma atividade e passa a ser um efeito que sobrevém à realização da atividade à qual pertence. Enfim, o ganho conceitual desta 
nova definição é que o prazer não deve ser considerado nem bom nem mau nele mesmo, mas, por acompanhar uma atividade boa ou má, ele pode ser bom ou mau. Não há, portanto, uma concepção essencialista do valor moral do prazer. Afinal, como a sua existência e essência dependem absolutamente da atividade à qual ele acompanha, é possível sustentar que a qualidade moral do prazer depende da qualidade moral desta atividade e o valor atribuído a esta atividade, por sua vez, depende do bom julgamento do homem virtuoso.

Ao terminarmos a primeira parte do livro, concluímos que a concepção aristotélica de prazer permite que o desejo, sobretudo o apetite, possa ser educado. Entretanto, não basta sabermos que o desejo pode ter prazer com o que é bom, é preciso compreender, por um lado, como ele pode passar a ter como objeto aquilo mesmo que a razão apreende como um bem e, por outro, como a razão pode atuar sobre o desejo. Mais precisamente, que operação racional atua sobre o desejo no processo formativo do caráter e na constituição do fim da ação. Em suma, na segunda parte do livro, "O desejo segundo Aristóteles", passamos a investigar como a educação do desejo se realiza.

A pergunta sobre como a razão pode atuar no desejo com vistas a constituir o fim virtuoso implica determinarmos quais funções racionais são estas e como elas atuam. Vimos que Aristóteles claramente descarta a função contemplativa (theôrêtikos) ou científica (epistêmonikon), responsável por contemplar os princípios invariáveis do ser. Isso porque a função racional determinante na produção da ação deve ser prática, portanto, distinta da contemplativa. Aristóteles nos diz que esta função prática é essencialmente calculativa (logistikon), pois é capaz de calcular (logizesthai) e deliberar (bouleuesthai) os fatores variáveis e circunstanciais envolvidos na ação de modo a determinar o que deve ser feito.

Todavia, como vimos, a racionalidade prática, mesmo tendo a sua expressão máxima na função deliberativa, não poderia estar reduzida a ela, pois a deliberação é responsável exclusivamente pela apreensão dos meios e não do fim. Se assim estivesse reduzida, o problema da constituição racional do bom fim seria definitivamente aporético. Em poucas palavras, o problema consiste em esclarecer o seguinte ponto obscuro: a razão deve educar o desejo a ponto de poder participar na constituição do fim da ação, mesmo que não seja através de sua função deliberativa. A necessidade de a razão ser eminentemente ativa na formação do caráter e na constituição do fim desejado é evidente; o que, porém, não é assim tão transparente é saber qual tipo de função racional pode atuar em conformidade ao desejo. 
Evidentemente, para solucionarmos esta dificuldade, devemos supor a existência de uma outra função racional, distinta da investigação deliberativa, que atue na constituição do objeto de desejo. A título de diferenciação da função deliberativa, chamamo-la, faute de mieux, de persuasiva. Apesar de o filósofo não a ter nomeado, ele a pressupõe e a descreve como uma certa visão do fim virtuoso. Vimos que Aristóteles parte do pressuposto de que o virtuoso vê (horan) o que é bom a ser feito e vê corretamente (horosin orthos). Dizer isto nada mais é do que dizer que o desejo põe (tithênai) o fim apreendido pela reta razão em sua função persuasiva e não deliberativa, uma vez que fora persuadido por ela. Dispor um fim, em termos gerais, significa perceber o que é preciso ser feito diante das circunstâncias que se apresentam e persuadir o desejo a desejar isto mesmo que fora percebido.

Neste sentido, seria falso atribuir ao filósofo o conceito de vontade na tentativa de solucionar este problema. A vontade, como vimos, pressupõe que o querer (boulêsis) seja um desejo absolutamente racional ou que a razão possa ser ela mesma capaz de desejar o fim por ela concebido. Aparentemente, o conceito de vontade soluciona esta dificuldade, como procuraram mostrar alguns filósofos medievais e modernos, mas esta não é e nem poderia ser a solução de Aristóteles. Assim, pretendemos mostrar como é equivocada a interpretação que lhe atribui tal conceito. Ademais, a riqueza da ética aristotélica encontra-se justamente em outra solução que não naquela proposta pelo conceito de vontade.

Se não é adequado delegar a Aristóteles o papel de fundador do conceito de vontade, embora a sua concepção de escolha deliberada (prohairesis), conjugada ao querer (boulêsis), incite tal interpretação, verificamos que outra solução a este dilema é possível. Para tanto, foi preciso investigar os tipos de funções racionais e como elas podem atuar na determinação do fim. Podemos dizer, grosso modo, que haveria duas funções racionais propriamente práticas: a deliberativa, que concerne aos meios, e a persuasiva, que concerne aos fins, isto é, que educa e persuade o desejo a tomar como seu objeto o que fora determinado corretamente como sendo bom.

A função deliberativa é responsável pela apreensão dos meios e, no caso do homem bom, pelos bons meios e pela avaliação moral do fim; portanto, ela não atua direta e imediatamente sobre o desejo, visto que não podemos escolher o que iremos desejar, mas se iremos realizar ou não o que já desejamos. Vimos que a constituição do fim desejado antecede à deliberação e, portanto, à escolha deliberada. Isso significa que ele não é fruto de uma escolha, mas, ao contrário, 
a escolha tem como causa o fim desejado; pois a escolha é um desejo deliberado pelos meios capazes de realizar certo fim. A escolha, portanto, é o desejo oriundo da investigação deliberativa, cujo objeto é um meio realizável aqui e agora em vista de um fim já dado. Quanto ao fim propriamente, a escolha não o constitui, mas apenas o aprova ou não.

É possível reconhecer um tipo de função racional exterior ao agente durante o processo de formação do caráter. No processo formativo, vimos que a razão que atua na educação dos desejos da criança lhe é exterior, portanto, pode ser compreendida como uma racionalidade presente nos conselhos, censuras e elogios dos adultos. Basicamente, a educação moral dos desejos significa educar a criança a ter prazer e dor com o que se deve. Esta trajetória pode ser descrita do seguinte modo: ao mesmo tempo em que a criança vai sendo orientada pela autoridade exterior, ela vai gradualmente aprendendo a discriminar o certo do errado e assim vai criando uma espécie de sensibilidade moral e se tornando capaz de tomar decisões por conta própria. Assim sendo, podemos concluir que a educação moral é justamente a realização da passagem entre o agir virtuosamente sem ser virtuoso ao agir virtuosamente sendo virtuoso; da passagem do agir por autoridade exterior ao agir por decisão própria desejando o fim virtuoso em vista dele mesmo.

Uma vez de posse da razão, o agente pode corrigir o seu caráter através da mudança de hábito, o que implica conhecimento de si. Isso porque, nos casos em que a razão ainda não foi inteiramente corrompida, o agente pode procurar corrigir seus próprios defeitos e aperfeiçoar seu caráter através do "autoconhecimento" e da "cura pelo contrário". Conhecendo a si mesmo e adquirindo bons hábitos, o adulto pode educar seus próprios desejos e corrigir suas próprias tendências e propensões, de modo a atingir a disposição mediana. Neste caso, o modo de atuação da razão parece ser primordialmente avaliativo e controlador.

A função persuasiva da razão, portanto, atua tanto de modo indireto na constituição do fim, na medida em que é responsável pela aquisição das disposições morais, como de maneira direta, na medida em que é capaz de persuadir o desejo a desejar o que ela apreendeu como sendo bom. Podemos inferir que a razão, por meio da determinação da ação, atua indiretamente sobre o desejo, portanto, sobre o fim da ação e, por meio da persuasão, atua diretamente sobre o desejo, portanto, na determinação do fim da ação.

A atuação direta da razão sobre o objeto de desejo, por sua vez, está condicionada à educação prévia dos desejos, portanto, à atuação da razão na formação 
do caráter virtuoso. Sabemos que, para que a razão possa apreender verdadeiramente o que deve ser feito, ela precisa estar em harmonia com o desejo, ou seja, a correta apreensão racional do fim pressupõe a existência de uma disposição em desejar o que é bom. Isso significa que, como pretendemos ter mostrado, há precedência da educação do desejo ao bom uso da racionalidade no âmbito das ações e emoções. Em poucas palavras, é preciso estar afetivamente predisposto para que a nossa razão possa perceber a melhor ação a ser realizada em dada situação particular. Para ver o que é bom a ser feito é preciso querer ver desse modo.

Procuramos mostrar a evidente imbricação entre desejo e razão, na medida em que a razão depende de um desejo educado para que ela possa exercer sua persuasão de modo adequado, e o desejo depende da razão para que ele possa ser educado e, consequentemente, possa ter como objeto o que é bom de fato. Por isso, foi imprescindível discriminar os modos de atuação da razão na formação do caráter, bem como na constituição do fim da ação.

A análise da atuação da razão durante e posteriormente à formação do caráter virtuoso nos permitiu sustentar a tese da precedência da educação dos desejos à aquisição plena da virtude. Argumentamos que, mesmo que a razão seja naturalmente capaz de julgar o que é bom, a educação prévia dos desejos é necessária para que esse correto julgamento ocorra. Ou seja, é preciso primeiramente se habituar a desejar o que é moralmente bom para que a razão possa estar apta a apreender o que é realmente bom e o agente possa passar de um estado de formação do caráter para um estado em que se é propriamente virtuoso. Por isso, somente alguém que já seja virtuoso poderá conceber por si mesmo a ação virtuosa e dar as boas razões para tanto. Alguém que esteja em processo de aquisição da virtude, por sua vez, dependerá fortemente dos conselhos para orientar suas ações, pois que sua racionalidade não adquiriu a autonomia prática própria do homem com o caráter já constituído.

Uma vez constituído o caráter, a razão que antes era externa ao agente, passa a estar sob o seu domínio. Esta racionalidade prática própria ao agente moral já adulto possui, ao menos, duas funções essenciais: uma responsável pela apreensão dos meios, a deliberativa, e outra responsável pela apreensão do fim. O virtuoso é aquele que faz uso maximamente da racionalidade prática em ambas as funções, pois ele apreende verdadeiramente tanto o bom fim e persuade o desejo a desejá-lo, como os bons meios.

Chegamos assim ao seguinte ponto da investigação: vimos que a educação do desejo é necessária, restando-nos ainda compreender como ela é possível e, 
sendo possível, como ela se realiza. Em primeiro lugar, quanto à sua possibilidade, já sabemos que a alma humana é constituída de modo que a razão pode participar perfeitamente do desejo persuadindo-o. Todavia, não basta compreender que o desejo possa desejar o fim virtuoso, é preciso investigar como é possível que ele venha a desejá-lo. Neste sentido, em segundo lugar, precisamos ter em mente que a natureza de nossa alma, segundo Aristóteles, viabiliza a educação dos desejos através da participação da razão na parte desiderativa. Ou seja, a alma está estruturada de tal modo que a faculdade desiderativa é híbrida entre a faculdade intelectiva e a vegetativa, entre a posse e a ausência de razão, pois ela é um movimento que provém da parte não racional, mas que, ao mesmo tempo, pode participar da parte racional. Por isso, em alguma medida, a razão deve ser capaz de participar do desejo, e este deve ser capaz de participar da razão. Esta possível comunicação entre desejo e razão nos fornece a condição de possibilidade do desejo ser educado.

Posta a possibilidade, segue-se a pergunta sobre como ele é educado. Para que o desejo seja educado, é preciso haver uma racionalidade capaz de educá-lo. A educação do desejo deve ser compreendida como o processo de formação do caráter, de aquisição da virtude através do habito em desejar o que é bom segundo o julgamento correto. Isso porque é o julgamento correto, aquele tal qual faria o virtuoso (spoudaios), que determina o que é bom (agathos) e belo (kalos). O bom e belo, por sua vez, são também ações prazerosas em si mesmas e para aquele que os deseja em vista deles mesmos. Assim, a operação desiderativa ideal é justamente aquela do homem bom, ou seja, aquela daquele que sabe encontrar a sua felicidade e prazer no que é propriamente virtuoso, pois já habituou o seu desejo a ser conforme a reta razão.

Isso significa que, ao ter educado seus desejos, o homem virtuoso passa a desejar e a achar prazeroso o que é bom segundo o julgamento correto. Por isso, o que ele julga ser bom lhe aparece como prazeroso. Já para o vicioso, ao contrário, o que lhe aparece como prazeroso é o que ele julga ser bom. Em suma, o homem bom é o padrão (kanon) e a medida (metron) para o que é prazeroso e penoso. Por isso, o que é considerado prazeroso para o homem bom também é prazeroso por natureza. O que é penoso para o homem bom, mas prazeroso para alguns, assim o é por corrupções (phthorai) ou por doenças (lumai). Desse modo, o vicioso sente prazer com o que não é naturalmente prazeroso, todavia não deixa de ter prazer, mesmo que este seja excessivo e contrário à natureza. 
Em outros termos, educar o desejo não é senão tornar-se moralmente virtuoso. Como o desejo é naturalmente a busca indiscriminada por prazer e a recusa de qualquer dor, educar o desejo significa, sobretudo, educar a ouvir a razão e a ter prazer e dor com o que se deve. O desejo, uma vez educado, passa a ter como objeto o bem apreendido, na particularidade da ação, pela razão. Assim, o desejo educado é aquele cujo objeto particular realizável aqui e agora também é uma expressão do desejo pelo fim último, isto é, pela felicidade. O desejo não educado, por sua vez, é próprio das crianças e dos animais, bem como dos adultos que vivem cegamente segundo os seus afetos, sem ter ideia do que é belo e verdadeiramente prazeroso, ou seja, são aqueles que visam o prazer de modo insaciável e indiscriminado: os adultos viciosos, como o perverso (kakos) e o intemperante (akolastos), e aqueles que ainda não são propriamente virtuosos nem viciosos, como os controlados (acrático) e os descontrolados (encratês).

Ao contrário das figuras morais do fracasso, o virtuoso se encontra numa harmonia tal que o que a razão vê como sendo o melhor, o desejo deseja. Em suma, a educação moral parece ser condição simultânea da apreensão racional verdadeira do bem e do desejo que a toma como objeto, ou seja, o virtuoso vê e imediatamente é persuadido a desejar o que deve ser feito. E assim o faz porque está previamente disposto a fazê-lo. Em outros termos, a educação do desejo é condição para que a razão seja capaz de apreender verdadeiramente o bom fim. E verdadeiramente quer dizer não apenas ver o que deve ser feito (isto o vicioso e o descontrolado também são capazes), mas persuadir o desejo a ter prazer com o que é correto, isto é, ver verdadeiramente significa apreender como bom e também prazeroso isto que deve ser feito.

Enfim, se para Aristóteles a habituação é o meio pelo qual a virtude pode ser adquirida, certamente ela não poderia ser uma dádiva divina ou natural, nem, como queria Sócrates, fruto de ensinamento. Vimos que a ética aristotélica, em oposição às posições intelectualista e naturalista, não pressupõe que a razão seja autônoma o suficiente para determinar o fim da ação segundo o conhecimento do bem e do mal, nem que ele seja dado por uma natureza inata boa ou má, porém pressupõe que apenas a razão seja capaz de apreender o que é verdadeiramente bom.

É bem sabido que o clássico problema do alcance e do limite do conhecimento na determinação da ação moral já é objeto de disputa entre Aristóteles e Sócrates. Diante do projeto socrático intelectualista, para o qual o conhecimento do bem é causa suficiente da ação virtuosa, Aristóteles, com a sua concepção 
da aquisição da virtude por hábito, limita o papel do conhecimento ao pressupor que a determinação da ação depende essencialmente de um elemento não racional, a saber: o desejo. Afinal, a finalidade de nossas ações é justamente o que desejamos. Entretanto, como o conhecimento do bem não poderia ser causa suficiente, mas apenas necessária da ação, um dos problemas centrais da ética aristotélica consiste em delimitar em que medida razão e desejo, saber o que é bom e querer o que é bom, são causas da ação. Por isso, tendo em vista que a determinação da boa ação depende essencialmente que a sua finalidade seja boa, o objeto de nossa investigação foi o problema da constituição do fim, cuja apreensão correta pressupõe a aquisição da virtude moral e se traduz na bela harmonia entre razão e desejo.

Podemos concluir este livro dizendo que a solução aristotélica para o problema da constituição racional do fim virtuoso não se resolve com o conceito de vontade, mas com o que podemos entender por razão persuasiva. A razão é capaz de discriminar corretamente as circunstâncias particulares de modo a encontrar o meio termo a ser desejado e almejado na ação. Esta retitude discriminativa, esta justeza e agudeza na razão somente podem ocorrer naquele que está previamente preparado em termos afetivos, isto é, que seja afetivamente capaz de ver o melhor. Ou seja, o bom uso da razão na apreensão do fim está condicionado ao bem-estar afetivo próprio do caráter virtuoso. Trata-se, antes, de ser afetivamente capaz de julgar o que é de fato bom do que de ser racional o suficiente para dominar os afetos. Em outras palavras, é preciso haver engajamento afetivo para que a ação seja propriamente correta. A razão só vê o que é certo porque estamos afetivamente propensos a ver, porque queremos ver assim. Os afetos, ao se constituírem como disposições, atuam como certos padrões ou regularidades; e estas nada mais são do que modos de raciocinar e perceber. Mais do que o conhecimento sobre o bem, são os afetos que condicionam a percepção do que é moralmente relevante; dentre eles, a voz pungente é a do desejo. 